\title{
MEDICAMENTOS E PLURALISMO TERAPÊUTICO \\ Práticas e lógicas sociais em mudança \\ [Noémia Lopes (org.), 2010, Porto, Afrontamento]
}

\author{
David Tavares
}

Em termos gerais, a problemática em análise no livro organizado por Noémia Lopes, intitulado Medicamentos e Pluralismo Terapêutico. Práticas e Lógicas Sociais em Mudança, insere-se numa área temática específica do campo da Sociologia da Saúde que se reporta à medicação e aos medicamentos, pouco explorada em Portugal ou mesmo em termos internacionais, pelo menos com a complexidade e profundidade com que é nesta obra.

O produto da presente publicação representa, de certa forma, uma continuidade da profícua investigação anterior desenvolvida pela sua autora/organizadora nos últimos anos, cujos resultados têm sido divulgados em diversas publicações que incluem as principais revistas de referência sociológica em Portugal (Sociologia, Problemas e Práticas; Revista Crítica de Ciências Sociais). Trata-se de uma continuidade dinâmica, pois acrescentam-se um conjunto significativo de novos dados e de novas pistas de reflexão, resultantes do trabalho de investigação recentemente concluído, que se consubstanciam como um forte contributo para o conhecimento desta problemática, centrada nas práticas de pluralismo terapêutico, definidas como "o consumo conjugado ou alternado de recursos medicamentosos de natureza diversa" e por vezes "de sinal contrário", que não se restringem aos medicamentos químicos mas abrangem igualmente os medicamentos naturais e os alimentos terapêuticos, categorias onde se incluem, por exemplo, a gama variada de medicamentos naturais tradicionais e os nutracêuticos ou alimentos funcionais.

O livro está organizado em cinco capítulos referentes às quatro dimensões abordadas relativamente aos consumos terapêuticos, nomeadamente o pluralismo terapêutico, as fontes de informação, a percepção e gestão do risco e os investimentos na saúde, acrescentando-se um último referente à reflexão metodológica. A bibliografia referenciada no final de cada capítulo constitui, aliás, um excelente ponto de partida para os futuros interessados no estudo desta problemática. Vale a pena referir, relativamente à organização do livro, que da sua leitura ressalta uma forte continuidade entre os vários capítulos, provavelmente devido ao facto de ter sido adoptada uma estrutura comum a todos eles, contrariando a tendência frequente para se verificar alguma descontinuidade e dispersão da análise quando as diferentes partes são redigidas por autores diferentes (Noémia Lopes, Telmo Clamote, Hélder Raposo, Elsa Pegado e Carla Rodrigues).

Tendo como referencial permanente o trabalho de investigação realizado, os autores procedem a um mapeamento rigoroso das formas plurais que caracterizam os consumos terapêuticos, a partir de uma análise quantitativa elaborada com base nos resultados de um inquérito aplicado a amostras muito amplas $(n=1500+$ 400) e, por outro lado, operam uma categorização exaustiva dos discursos dos 
indivíduos, a partir de uma análise predominantemente qualitativa, realizada com base nos depoimentos expressos nas entrevistas semiestruturadas (75).

Num e noutro caso, os resultados apresentados traduzem de forma minuciosa as diferentes lógicas do consumo terapêutico, fornecendo, por um lado, importantes indicações acerca das tendências gerais relativamente a estes consumos, nas diferentes dimensões que se constituíram como objecto de estudo (pluralismo terapêutico, fontes de informação e investimentos informacionais, percepção e gestão do risco, investimentos na saúde), bem como acerca das tendências relativas à distribuição por sexo, idade, escolaridade e território (predominantemente rural e predominantemente urbano) e, por outro lado, caracterizam os diferentes consumos terapêuticos nas várias dimensões em estudo, através da criação de um conjunto rigoroso e exaustivo de categorias/tipologias.

Não cabendo no espaço desta recensão a referência pormenorizada ao amplo conjunto de resultados apresentados nem aos aspectos mais específicos da reflexão aprofundada a que esses resultados deram origem, vale a pena explicitar algumas tendências gerais, nomeadamente a coexistência de tendências (só) aparentemente contraditórias e paradoxais, como o aumento do pluralismo terapêutico e simultaneamente o aumento da circulação e do consumo de medicamentos químicos, num quadro de "farmacologização do quotidiano"; a articulação entre "critérios tradicionais, como a experiência corporal [...] com novas possibilidades de apropriação, comparação e validação da informação pericial", na relação que os indivíduos estabelecem com as diversas fontes de informação; "as formas complexas e contraditórias de percepção e de resposta face ao risco que os indivíduos assumem no dia-a-dia dos seus contextos circunstancialmente situados"; "o carácter contingencial e processual de orientações e de investimentos de saúde".

Ao longo do livro, o leitor é remetido para um permanente rigor teórico e metodológico, que preside à apresentação dos resultados do trabalho de investigação realizado e ao debate das questões elencadas, com uma "lucidez crítica" considerável, se tivermos em conta estarmos perante um tema susceptível de múltiplas mistificações e generalizações mais ou menos simplistas que, como é sabido, circulam na sociedade e também em diversos meios científicos, a propósito dos consumos terapêuticos. Neste sentido, a análise aqui encetada tem o valor acrescentado inerente ao seu carácter desmistificador.

A análise sobre os consumos terapêuticos realizada neste livro contribui também para o debate mais vasto de questões transversais que se afiguram como centrais e emergentes na agenda actual da Sociologia da Saúde, nomeadamente as que se reportam aos processos sociais e ao contexto das transformações sociais. Entre essas questões, figura seguramente o modo como a tendência para o progressivo crescimento da pluralização dos consumos terapêuticos se inscreve em novas percepções, investimentos e práticas relativamente à saúde e à doença, construídas num quadro de recomposição e reconfiguração da relação entre os universos periciais e os universos leigos.

David Tavares. Docente na Escola Superior de Tecnologias da Saúde de Lisboa (ESTeSL). E-mail: david.tavares@estesl.ipl.pt 